\title{
Breast Lesion
}

National Cancer Institute

\section{Source}

National Cancer Institute. Breast Lesion. NCI Thesaurus. Code C159594.

A localized pathological or traumatic structural change, damage, deformity, or discontinuity of the breast. 